
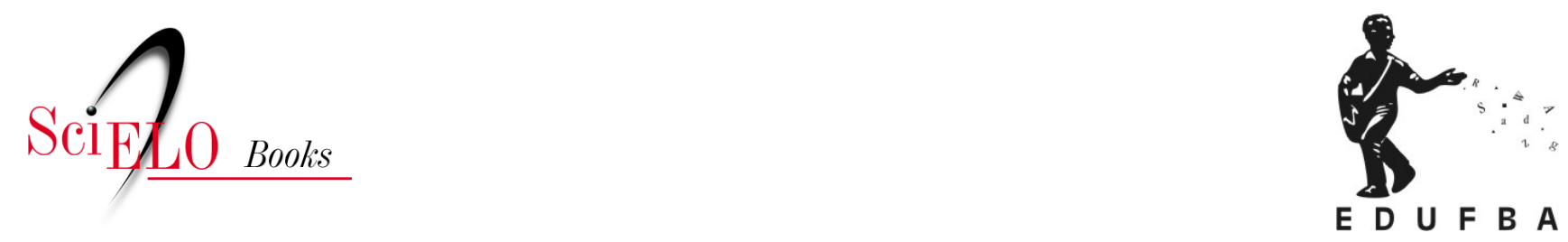

\title{
Processo laboral e a saúde dos trabalhadores em centros de atenção psicossocial
}

\author{
Maria de Fátima Prates Budde \\ Tânia Maria de Araújo
}

\section{SciELO Books / SciELO Livros / SciELO Libros}

BUDDE, M.F.P., and ARAÚJO, T.M. Processo laboral e a saúde dos trabalhadores em centros de atenção psicossocial. In: FERNANDES, R.C.P., LIMA, M.A.G., and ARAÚJO, T.M., comps. Tópicos em saúde, ambiente e trabalho: um olhar ampliado [online]. Salvador: EDUFBA, 2014, pp. 153-180. ISBN: 978-65-5630-012-2. https://doi.org/10.7476/9786556300122.0009. \section{International license.}

All the contents of this work, except where otherwise noted, is licensed under a Creative Commons Attribution 4.0

Todo o conteúdo deste trabalho, exceto quando houver ressalva, é publicado sob a licença Creative Commons Atribição 4.0. 


\section{Processo laboral e a saúde dos trabalhadores em centros de atenção psicossocial}

Maria de Fátima Prates Budde

Tânia Maria de Araújo

\section{Introdução}

Diversas mudanças, em diferentes âmbitos, vêm tornando cada vez mais complexo o cenário de práticas do campo da saúde mental no Brasil. Dentre os temas abordados pela IV Conferência Nacional de Saúde Mental Interdisciplinar, realizada em dezembro de 2010, destacam-se a: ampliação e difusão territorial dos novos serviços, com incremento do número de trabalhadores de saúde mental, em um contexto de terceirização e precarização do emprego, e com amplo contingente de trabalhadores com inserção recente nas atividades profissionais e no ativismo político do campo; a diversificação do movimento antimanicomial [...]; a presença e participação mais ativa e autônoma de usuários e familiares; a presença de diversas agências e atores políticos intersetoriais; as novas características do trabalho e de tecnologia em saúde mental no SUS, [...]; uma expansão de serviços públicos de saúde mental que não foi acompanhada por uma oferta e capacitação compatível de profissionais psiquiatras para o trabalho em saúde pública, gerando uma carência de profissionais em saúde mental.

Como ilustrado nos temas citados acima, as mudanças do modelo de atenção redefiniram os processos de trabalho, inauguraram novas exigências do trabalho e introduziram muitos, novos e complexos desafios.

A reestruturação do modelo de atenção em saúde mental no Brasil implicou novos modos de constituição dos serviços e, consequentemente, 
alterou a composição das equipes nos novos dispositivos de tratamento, em particular, dos Centros de Atenção Psicossocial (CAP). As mudanças no modo de constituição dos serviços produziram alterações no processo de trabalho existente (no objeto, nos instrumentos e nas próprias atividades), e, consequentemente, na composição das equipes. As alterações decorrentes do reordenamento dos serviços de saúde mental, por sua vez, geraram significativa modificação dos atributos técnicos requeridos dos diferentes profissionais que, a partir deste momento, tiveram que lidar com novas demandas e atribuições.

Os trabalhadores em saúde mental se deparam, ainda hoje, com o desafio de implantar e implementar um novo modelo de atenção. Considerando todas as interfaces que o trabalho da atenção psicossocial apresenta, espera-se que estes trabalhadores tenham os conhecimentos necessários para intervir em diferentes campos de atuação; na realidade os técnicos devem desdobrar-se em identidades e atribuições múltiplas, com o objetivo de atuar no centro de um território virtual e de uma rede de subjetividades de uma comunidade. Espera-se deste novo trabalhador que ele possa intermediar as mudanças sociais necessárias ao resgate dos direitos de cidadania enquanto promove a inclusão social de pessoas portadoras de transtornos mentais. Este técnico deverá dominar vários e complexos campos do conhecimento: técnico, social, ético, jurídico e político. (DELGADO, 1989; BRASIL, 2004; BICHAFF, 2006; LANCMAN, 2008)

Os novos serviços em saúde mental se propõem a lidar, na realidade, com novos recursos que, iniciando pela estrutura física dos serviços, passam pelos conhecimentos especializados das diferentes áreas profissionais e aplicação de novas técnicas (por exemplo, oficinas com diferentes finalidades, incluindo geração de renda). Nos Centros de Atenção Psicossocial, todos os agentes e todos os meios que vierem a ser utilizados, necessitam ser apreendidos para poderem ser coordenados com a finalidade de transformar o objeto de trabalho, o usuário, realizando, desta maneira, a proposta da reabilitação psicossocial. (MILHOMEN et al., 2007)

Observa-se, entretanto, que as novas equipes, ao assumirem a responsabilidade de implantarem o novo modelo preconizado de atenção em saúde mental, o fazem sem dispor, muitas vezes, de recursos técnicos e de formação e capacitação para fazê-lo adequadamente. (OLIVEIRA et 
al., 2003; BICHAFF, 2006; MILHOMEN et al., 2007; RABELO; COUTINHO, 2009)

Em virtude da importância que os CAPS adquiriram no processo de reestruturação da atenção em saúde mental, por sua expansão e difusão, pelo seu potencial em abarcar parcela significativa da população brasileira portadora de transtorno mental crônico e pelo contingente de trabalhadores envolvidos, procura-se neste estudo refletir sobre o trabalho desenvolvido nesses centros, utilizando como referência a teorização de Laurell e Noriega (1989) sobre processo de trabalho em saúde a partir do modelo de desgaste e nos conceitos teóricos sobre a relação prazer e sofrimento no trabalho. (DEJOURS, 2009)

Assim, este estudo tem como objetivos: descrever as características do processo de trabalho de profissionais em saúde mental e a percepção dos trabalhadores sobre as cargas laborais às quais estão submetidos; e identificar características dos diferentes tipos de cargas de trabalho e os riscos à saúde mental a que os trabalhadores estão expostos nos seus cotidianos de trabalho.

A pretensão deste estudo é ser mais uma peça na construção do arsenal desse novo modelo de assistência à saúde mental, particularmente, no que diz respeito às novas práticas desenvolvidas pelos trabalhadores nesses serviços e no fato de possibilitar uma melhor compreensão dos aspectos relacionados ao fator humano, fundamental na consolidação dos princípios da Reforma Psiquiátrica.

\section{Metodologia}

\section{Bases conceituais e teóricas adotadas}

Este estudo foi construído a partir das bases conceituais e metodológicas do modelo de desgaste de Laurell e Noriega (1989), ancorado no modelo operário italiano. Adotou-se também os conceitos teóricos sobre a relação prazer, sofrimento e trabalho propostos pela psicodinâmica do trabalho, na perspectiva da escola dejouriana. (DEJOURS, 2009)

O método de investigação utilizado para a pesquisa foi baseado nos princípios do Modelo Operário Italiano. (LAURELL; NORIEGA, 1989) 
Nesta abordagem, é proposto o uso de entrevistas coletivas com o objetivo de fazer um levantamento dos dados empíricos que permitam compreender as relações entre os processos de trabalho, a saúde física e psíquica, e o papel dos trabalhadores na construção do conhecimento e na transformação da realidade. O modelo possibilita ainda, aos trabalhadores, a reconstrução dos processos de trabalho, com identificação de danos e riscos, aos quais podem estar expostos. (FACCHINI et al., 1991)

Nesse modelo, nas investigações das relações entre trabalho e saúde, o foco é direcionado a duas categorias centrais de análise: "as cargas de trabalho" e os "processos de desgaste". $\mathrm{Na}$ análise do processo de trabalho, o conceito de "cargas de trabalho" busca ressaltar os elementos que interatuam dinamicamente entre si e o corpo do trabalhador, gerando processos de adaptação que se traduzem em desgaste. O conceito de carga tem como finalidade possibilitar uma análise do processo de trabalho que extrai e sintetiza os elementos que determinam de modo importante, o nexo biopsíquico da coletividade operária e confere a esta um modo histórico e específico de "andar a vida". (ARAÚJO, 2004)

O entendimento do "desgaste" como uma categoria integrada ao de "cargas de trabalho" permite introduzir no pensamento uma representação coerente do que são as transformações negativas originadas pela interação dinâmica das cargas nos processos biológicos e psíquicos humanos. O desgaste é definido como a perda de capacidade efetiva e/ ou potencial, biológica e psíquica, ou seja, não se refere a um processo particular isolado, mas sim ao conjunto dos processos biopsíquicos. (LAURELL; NORIEGA, 1989)

A relação entre processo de trabalho, cargas de trabalho e de desgaste, possibilita entender e predizer quais são os processos que consomem a força de trabalho ou desgastam as capacidades consideradas vitais para o trabalhador. Desta forma, à medida que se sabe que tipo de processo está presente num posto de trabalho, pode-se identificar quais são as principais cargas e os traços gerais do padrão de desgaste.

$\mathrm{Na}$ produção do conhecimento sobre os processos de trabalho em saúde mental e percepção de riscos a que estão submetidos os trabalhadores, foram utilizados os conceitos de cargas laborais propostos por Facchini (1993), Laurel e Noriega (1989) que incluem: a) cargas físicas; 
b) cargas químicas; c) cargas biológicas; c) cargas mecânicas; d) cargas fisiológicas; e) cargas psíquicas.

Em qualquer processo de trabalho podem ser encontrados estes tipos de cargas, com menor ou maior intensidade, que podem interagir entre si, potencializando ou somando-se no contexto individual e coletivo da vida dos trabalhadores.

Além do conceito de cargas de trabalho, proposto no modelo de desgaste, foram também utilizadas neste estudo as contribuições do modelo da psicodinâmica do trabalho.

O interesse maior da psicodinâmica é analisar o trabalho, seu conteúdo, sua significação e suas formas múltiplas de produção de sofrimento ou de prazer. (DEJOURS, 2009) Nesta abordagem, as relações que se estabelecem entre o trabalhador e o seu trabalho podem ser apreendidas por meio da compreensão dos procedimentos defensivos que ajudam os trabalhadores a resistir psiquicamente à agressão que compõe determinadas formas de organização do trabalho. Esse referencial subsidia a discussão de como os trabalhadores fazem para resistir às agressões ao seu funcionamento psíquico.

Na proposição da psicodinâmica do trabalho, o sofrimento implica um estado de luta do indivíduo contra as pressões ligadas à organização do trabalho. Por organização do trabalho entende-se a divisão do trabalho, isto é, a divisão de tarefas, os ritmos impostos e os prescritos, as hierarquias, repartições de responsabilidades e os sistemas de controle. (DEJOURS, 2009)

Dentre os conceitos utilizados nesta teoria destacam-se o do prazer no trabalho, de sofrimento criativo e de sofrimento patogênico. Através destes, pode-se entender as relações que se estabelecem entre a organização do trabalho e o sofrimento psíquico. A fala do trabalhador tem papel destacado nesse modelo - a análise da fala e dos silêncios dos trabalhadores permite compreender as formas subjetivas de estruturação da vida mental no trabalho: sua fonte de prazer e de sofrimento e os modos coletivos de vivência da vida no trabalho. (DEJOURS, 2009)

Nesta teoria, a linguagem pode ser mobilizada como expressão da dinâmica do reconhecimento dos problemas, como atividade semiótica que estrutura a realidade do trabalho e como intermediadora da ação. $\mathrm{Na}$ teoria dejouriana e no modelo de desgaste, o trabalhador é compreendido como o portador de uma história singular pré-existente e capaz 
de construir uma análise muito precisa da organização e das situações de trabalho. (COUTINHO NETO, 1998; DEJOURS, 2004)

\section{Local da pesquisa e sujeitos entrevistados}

Este estudo foi realizado no município de Salvador, capital do Estado da Bahia. Administrativamente, o município encontra-se dividido em 12 Distritos Sanitários. Em Salvador, estavam implantados, em 2010, 19 CAPS, sendo 18 municipais e um criado por uma Organização Não Governamental (ONG), distribuídos pelos distritos sanitários. Em seis Distritos Sanitários foram implantados mais de um CAPS, e esta decisão foi tomada após a observação de critérios técnicos tais como: alta concentração populacional, alto índice de população de baixa renda, de violência e "grotões" de miséria, região com concentração de turistas e de fácil aquisição de drogas, de dificuldade de acesso para outros serviços especializados, seja pela inexistência na proximidade ou pela considerável extensão territorial dos distritos. (MONTEIRO, 2007)

Inicialmente foram selecionados seis CAPS para a realização do estudo. Nas unidades escolhidas foram realizadas entrevistas coletivas com os trabalhadores em seus locais de trabalho.

Os critérios utilizados para a escolha das seis unidades foram: o tempo de credenciamento, composição multiprofissional das equipes, localização geográfica e a experiência reconhecida na área de saúde mental (trajetória de envolvimento com os novos modelos de atenção), pois, desta maneira, as equipes poderiam ter vivenciado a construção dos novos saberes e das novas práticas em saúde mental.

Os convites para a participação no estudo foram feitos, aos trabalhadores, nos próprios locais de trabalho, após uma campanha de sensibilização onde foi destacada a importância da participação e incorporação dos trabalhadores à pesquisa.

Ao todo, participaram das entrevistas 86 profissionais de saúde dos seis CAPS municipais incluídos na pesquisa.

Os CAPS selecionados estavam localizados nos Distritos Sanitários Barra/Rio Vermelho, Itapajipe, Cabula/Beiru, Boca do Rio e Centro Histórico; portanto, abrangiam áreas geográficas distintas, possibilitando avaliação de uma maior diversidade de situações. 


\section{Procedimentos do trabalho de campo}

Para a coleta de dados sobre o processo de trabalho em saúde mental e percepção de riscos, foram realizadas entrevistas semi-estruturadas conduzidas a partir de um roteiro previamente definido. O roteiro da entrevista abarcou quatro blocos de questões que incluíam:

1. Bloco I - Características da organização do trabalho;

2. Bloco II - Características do processo do trabalho;

3. Bloco III - Trabalho e saúde: exposição a riscos;

4. Bloco IV - Prazer e dor no trabalho cotidiano.

Como estratégia para delinear o percurso e permitir uma melhor aproximação com o objeto de estudo, as unidades foram visitadas para a apresentação da pesquisa e de seus objetivos, nas reuniões de equipe, por sugestão da própria equipe, considerando que este seria o único dia em que todos os profissionais se encontravam no local de trabalho.

As entrevistas tiveram uma duração média de uma hora e vinte minutos e foram gravadas com autorização prévia dos trabalhadores e transcritas posteriormente para a análise dos dados.

Os dados foram coletados nos meses de julho, agosto e setembro do ano de 2010.

\section{Análise dos dados}

A técnica da Análise de Conteúdo foi utilizada para a interpretação dos dados. Esta pode ser definida como um conjunto de instrumentos metodológicos, que visam obter, através de procedimentos sistemáticos e objetivos de descrição do conteúdo das mensagens, indicadores (quantitativos ou não) que permitam a inferência de conhecimentos relativos às condições de produção destas mensagens. (BARDIN, 2009) A análise de conteúdo é um processo de investigação utilizado para quantificar material qualitativo através de categorização e tabulação de dados obtidos em entrevistas, anúncios, recortes, propagandas, textos, documentos oficiais, discursos, dentre outros.

Minayo (2008) sintetiza o percurso do trabalho dos dados a partir da perspectiva da análise de conteúdo em três etapas. Na primeira etapa tem-se a pré-análise, que consiste na escolha dos documentos a serem analisados e na retomada dos pressupostos e dos objetivos iniciais 
da pesquisa. Deve-se indagar sobre as relações entre as etapas realizadas, elaborando indicadores que orientem a compreensão do material e a interpretação final. Esta pré-análise pode ser decomposta nas seguintes tarefas: leitura flutuante (o pesquisador toma contato direto e intenso com o material produzido); constituição dos Corpos (diz respeito ao universo estudado em sua totalidade e deve responder as seguintes normas de validade qualitativa: exaustividade, representatividade e homogeneidade); Formulação e reformulação dos pressupostos e objetivos (consiste na retomada da etapa exploratória, tendo como parâmetro a leitura exaustiva do material com base nas indagações iniciais). Nessa fase pré-analítica determinam-se a unidade de registro (palavra chave ou frase), a unidade de contexto (delimitação do contexto de compreensão da unidade de registro), os recortes, a forma de categorização, a modalidade de codificação e os conceitos teóricos mais gerais. Na segunda deve ser feita a exploração do material, que consiste numa operação classificatória que visa alcançar o núcleo de compreensão do texto e a busca de categorias pelo investigador. Na terceira etapa tem-se o tratamento dos resultados obtidos e interpretação.

A análise dos dados, feita neste estudo, seguiu os passos operacionais descritos por Minayo (2008), e permitiu o estabelecimento de relações entre as diferentes fontes, buscando articular o material empírico e o referencial teórico-metodológico adotado, na tentativa de obter respostas para os questionamentos e objetivos que nortearam este estudo.

Desse modo, a análise contemplou três etapas sintetizadas por Minayo (2008). Na primeira etapa foi feita a organização dos dados - primeiro contato com o material coletado. Na segunda etapa ocorreu a exploração do material - constituiu na exploração classificatória, visando à busca da compreensão do texto. Nesta fase realizou-se leitura flutuante, depois leitura exaustiva do material, sendo estabelecida a categorização. O critério eleito para obter o núcleo de compreensão do texto foi o de categoria temática, que foram obtidos dos temas utilizados nas entrevistas. Após a definição desses núcleos, os dados foram recortados, classificados e inseridos em seus respectivos núcleos. Os princípios da objetividade e da fidelidade foram observados para evitar as distorções que porventura surgissem. Na terceira etapa fezse o tratamento dos resultados obtidos e a interpretação - nesta etapa 
trabalhou-se na construção da síntese, na realização das interpretações, interrelacionando-as com o quadro teórico apresentado.

Para ordenamento e estruturação da análise buscou-se explorar os elementos/chave constantes no roteiro utilizado, organizando-se a análise com base na caracterização da organização e do processo de trabalho, percepção de riscos à saúde e elementos produtores de prazer e sofrimento no cotidiano laboral. Adicionalmente uma nova categoria analítica, pela importância registrada pelos trabalhadores, foi destacada e explorada na análise: a violência envolvida na cena de trabalho desses profissionais.

\section{Resultados e discussão}

\section{Característica do processo e da organização do trabalho}

O início de um dia de trabalho no CAPS começava quando as portas da unidade eram abertas e por elas passavam os usuários e os profissionais. Já na chegada os profissionais encontravam os usuários que chegavam muito cedo e uma demanda definida para atendimento.

Geralmente quando a gente chega aqui já é aguardado pelo usuário lá fora, né? Porque ele já vem demandando uma série de coisas do dia-a-dia, pergunta coisas referentes à medicação, das atividades que irá fazer. (COORDENADORA, CAPS 4 )

“[...] quando a gente chega, já começa a atender na porta, no portão já encontramos usuários demandando alguma coisa”. (PSICÓLOGO, CAPS 2)

O serviço encontrava-se organizado de modo que, normalmente, houvesse sempre um profissional de plantão - uma pessoa responsável pelo acolhimento, encaminhamento, e pelo apoio para as intercorrências e a recepção de familiares. Os serviços, a depender do local e da segurança, ficavam abertos das $8 \mathrm{~h}$ às $17 \mathrm{~h}$.

As tarefas diárias desenvolvidas pelos trabalhadores de CAPS eram compostas por oficinas terapêuticas e profissionalizantes, grupos terapêuticos, atendimentos individuais (psicoterapias, prescrição de medicamentos e orientações), visitas domiciliares, atendimento às famílias, 
trabalho comunitário de integração da rede, cuidados com a saúde física do usuário (marcação de consultas médicas e odontológicas), ações educativas de promoção do desenvolvimento da cidadania dos usuários e seus familiares, atividades externas de lazer, cumprimento de uma agenda com órgãos e instituições públicas, trabalho administrativo, atualização do prontuário, busca ativa, elaboração e acompanhamento do plano terapêutico individual, oficinas de geração de renda e assistência às Residências Terapêuticas ${ }^{1}$.

Havia a distribuição dos pacientes de referência pela coordenação e a determinação das prioridades era feita no acolhimento, onde se identificavam as necessidades dos usuários e, de acordo com as demandas, eram agendados os procedimentos e condutas a serem adotadas.

As assembleias com os usuários e reuniões de equipe aconteciam, em geral, semanalmente. Mensalmente os técnicos trabalhavam na confecção de Autorização para Procedimentos de Alta Complexidade (APACS) - que são formulários, que devem ser preenchidos pelos profissionais, para o registro do conjunto de procedimentos a que se refere à Portaria $n^{\circ}$ 189/02 e incluem: atendimento individual, atendimento em grupo, atendimento em oficinas terapêuticas, atendimento às famílias e atividades comunitárias.

A integração da equipe, em todas as entrevistas realizadas, foi descrita como boa pelos entrevistados; as divergências e os conflitos foram mencionados como desafios, uma forma de funcionamento baseada na discussão coletiva que elevava o crescimento profissional, conforme atestam os depoimentos dos trabalhadores: "O que eu acho enriquecedor é quando estamos discutindo casos aqui no CAPS, cada um dá sua opinião, cada um fala do seu olhar, isso enriquece muito e traz um grande aprendizado para a gente". (EDUCADOR FÍSICO, CAPS 3)

A interlocução para a divisão das tarefas era feita pela coordenação, geralmente nas reuniões de equipe. As tarefas eram direcionadas de acordo com a demanda e com o perfil e a especificidade profissional dos trabalhadores. As definições de papéis e de atribuições de cada

1 Os CAPS foram incorporados inicialmente como serviços estratégicos no Fundo de Ações Estratégicas e Compensações (FAEC) do Ministério da Saúde através das Portarias n 336/02 e ${ }^{\circ} 189 / 02$. Sendo assim, esses instrumentos normativos alteraram a fonte de financiamento dos CAPS e incluíram na Tabela SIA/SUS códigos para os grupos de procedimentos na área de saúde mental. Note-se que o valor de cada procedimento descrito na Portaria incluía todos os atos, atividades e materiais necessários à sua realização. (BRASIL, 2004) 
profissional neste novo modelo de atenção, no entanto, não estavam muito claras, o que gerava conflitos, mas podiam também estruturar possibilidades para o diálogo e para a construção de alternativas novas para o trabalho.

"Até há pouco tempo discutíamos o papel da enfermeira, seu lugar e as intervenções". (PSICÓLOGO, CAPS 5)

"Quando existem visões diferentes pode existir conflito, então, numa equipe multidisciplinar o desafio é grande, porque o modelo é novo e os conflitos aparecem, mas estes fazem com que a equipe cresça". (ENFERMEIRA, CAPS 1)

Desse modo, em todas as unidades estudadas, a organização do trabalho em saúde mental era, na percepção dos trabalhadores, a priori, concebido como um trabalho em equipe, estruturado a partir de definições coletivas estabelecidas em processos de discussão do grupo.

“[...] a ideia de uma equipe multiprofissional é boa, ela deve ter um vínculo de afetividade, companheirismo, de compreender a disponibilidade e especificidade de cada um, porque cada um é distinto". (MÉDICO, CAPS 1)

As definições que são estabelecidas nas reuniões das equipes de trabalho compõem a chamada grade de atividades ${ }^{2}$ cotidianas dos serviços. No entanto, concretamente, a realização das atividades diárias era estabelecida por situações diversas que demandavam atenção (nem sempre como previsto) e dependiam, também, do perfil da gestão e da coordenação dos serviços.

\section{O Ambiente de Trabalho}

A percepção dos trabalhadores sobre as cargas de trabalho evidenciou que os fatores mais relevantes para o desgaste sofrido estavam relacionados ao ambiente de trabalho, especialmente a infraestrutura física dos locais de trabalho (com destaque para as cargas físicas e biológicas).

2 Grade de atividades corresponde a um planejamento de atribuições e de responsabilidades pelas tarefas e ações em um dado período de tempo; incluem responsabilidade por casos de pacientes específicos e por atividades correlatas a cada trabalhador. É, portanto, um mapa de organização do trabalho de atenção à saúde mental em um período de tempo (atividades, responsável, tempo). 
As queixas registradas evidenciaram claramente a inadequação dos espaços utilizados para o serviço prestado. Dentre os problemas elencados, destacaram-se o calor intenso no verão, a falta de ventilação nas salas de trabalho de grupo, o barulho intenso oriundo da rua ou dos próprios usuários na unidade, umidade das paredes - o que facilitava a formação de fungos; falta de manutenção e higienização precária dos prédios e dos sanitários utilizados por todos. Portanto, constatou-se que os espaços físicos existentes não atendiam às necessidades dos serviços, sendo, em geral, construções alugadas que, para funcionar como um CAPS exigiam improvisações as mais variadas para que, minimamente, pudessem atender às demandas das atividades planejadas.

Outra dificuldade enfrentada pelos trabalhadores estava associada à falta de espaços reservados, nos quais, com uma determinada privacidade, fosse possível redigir as anotações nos prontuários, almoçar ou discutir algum caso sem serem interrompidos por algum usuário do serviço, como atestam os relatos dos profissionais: "A coordenação fez uma programação de ficar sempre um técnico de plantão, e ao meio dia, então, a gente queria ter um tempo também para poder descansar em paz [...]". (ASSISTENTE SOCIAL, CAPS 5) "Você está aqui escrevendo, aí o usuário abre a porta, em outro contexto você podia dizer, agora não, não interrompa, estou ocupado[...]”. (PSICÓLOGO, CAPS 5)

Afora as dificuldades de espaço e tempo para a necessária reflexão de cada caso atendido, cabe registrar a ausência de salas adequadas, reservadas, no qual seja possível estabelecer-se a possibilidade de acolhimento, de expressão de situações íntimas, muitas vezes dolorosas, sendo obstáculo muito significativo para o trabalho em saúde mental, pois impossibilita o mínimo da preservação da intimidade dos pacientes.

\section{As Cargas Laborais: as demandas excessivas em foco}

As atividades exercidas pelos trabalhadores de saúde mental tinham escopo amplo, com grande diversidade de atribuições e papéis, sendo um trabalho que exigia muito do trabalhador. As reclamações sobre as cargas laborais demonstraram que estes técnicos exerciam suas atividades sob alta pressão psicológica. As queixas mais frequentes foram de falta de tempo para realizar as atividades programadas, dificuldade no 
cumprimento da carga horária contratada, o fato da maioria dos trabalhadores cumprirem dupla ou tripla jornada de trabalho e exigência, por parte da gestão, para aumentarem o número de atendimentos.

"Você fica com a cabeça pesada porque tem de cumprir a carga horária em outro lugar”. (TERAPEUTA OCUPACIONAL CAPS 2)

Essa responsabilidade, muitas vezes, era vivenciada com sofrimento pelos trabalhadores:

"Angústia, uma palavra angústia [...] exatamente porque a gente tem as atividades de grupo, as oficinas que a gente planeja e temos de dar conta de uma quantidade de usuários referências". (ASSISTENTE SOCIAL, CAPS 2)

"A gente vem para o CAPS pensando em poder realizar todas as atividades que supostamente estariam programadas. No dia a dia não conseguimos realizar por conta das outras demandas que vão surgindo". (ASSISTENTE SOCIAL, CAPS 3)

Os profissionais consideravam que as várias demandas ocasionavam uma sobrecarga na rotina, pois além do trabalho manual, burocrático, havia o trabalho mental de reflexão e de busca de solução para os problemas que surgiam. Além disto, foi observado, no discurso dos profissionais, que estes assumiam, muitas vezes, o trabalho que deveria ser feito pelas secretarias de ação social e outros órgãos no município.

Além das demandas excessivas, os profissionais chamaram a atenção para a contínua necessidade de vigília que precisavam manter. O fato da clientela de um CAPS ser formada, na sua maioria, por pacientes com transtornos mentais severos e persistentes, e que, às vezes, apresentavam um comportamento de difícil previsibilidade, que podia mudar repentinamente, exigia que a equipe ficasse o tempo inteiro em estado de alerta.

[...] convivemos com pacientes com alto poder de agressividade, então o risco é grande, já se pegou paciente aqui que agrediu, de agressão física, paciente chegar aqui, eh, armado de faca, paciente chegar aqui com pedaço de espelho guardado na bolsa, guardado na sacola porque agrediu alguém, um vizinho [...], então a área em que nós trabalhamos é uma área de alta periculosidade. (ASSISTENTE SOCIAL, CAPS 6)

Outro aspecto destacado nas entrevistas referiu-se às situações de intervenção que não estavam previstas e que demandavam atenção 
imediata da equipe, impossibilitando que as atividades planejadas fossem executadas. Essas situações conformavam as chamadas intercorrências. Tais situações, não raro, dificultavam a manutenção da rotina diária criada e discutida nas reuniões de equipe, e sinalizavam a constante necessidade de replanejamento das ações a serem executadas no cotidiano do serviço. A análise do processo de trabalho descrito, mesmo superficialmente, parece apontar para um ponto de tensão nesta direção.

[...] e outra coisa é a sua intervenção também. E você tem de se policiar e perguntar por que a clínica te envolve o tempo inteiro? Estar modulando essa autocrítica é que é o fator estressor [...] eu poderia dizer: agora não, estou ocupado [...], enfim se ele está com uma demanda, você tem de intervir, e esse tempo inteiro de clinica é um grande estressor. (PSICÓLOGO, CAPS 5)

Estas situações que exigiam uma atenção imediata sem prévio planejamento, estabeleciam, no dizer dos trabalhadores, um paradoxo, dificultando a continuidade das atividades de rotina, necessárias para o alcance dos bons resultados nas condutas terapêuticas estabelecidas (requisito importante no tratamento de pacientes com adoecimento psíquico). Desta forma, evidenciou-se que o trabalho em saúde mental guardava sempre uma necessidade latente, que podia ou não se revelar no dia de trabalho, devendo o profissional estar atento ao seu entorno e pronto para atuar segundo a exigência que for explicitada.

"A rotina é fundamental para os grupos e oficinas, mas tem outra rotina clínica que não tem rotina: são as intercorrências". (PSICÓLOGO, CAPS 5 )

"São dois paradoxos: devemos planejar todas as atividades como necessidade de organizar o serviço e, por outro lado, o trabalho em saúde mental é algo muito dinâmico, muito vivo". (PSICÓLOGA, CAPS 2)

No enfrentamento da tensão entre o planejado e o inusitado, mobilizador de toda a atenção e intervenção no trabalho diário, destacouse o processo de cooperação e ajuda mútua entre os trabalhadores nas unidades. No geral, havia uma relação pautada por elevada cooperação, todos os profissionais presentes, ajudavam a cuidar dos mais variados acontecimentos diários, que faziam parte da rotina destes serviços.

"Voltando à rotina, voltamos à discussão da urgência/emergência, o usuário pode chegar aqui em crise, aí temos que encaminhar para algum lugar, então alguém vai". (PSICÓLOGO, CAPS 5) 
Entre as cargas psíquicas ou riscos capazes de provocar estresse ou tensão emocional destacou-se o fato de vários trabalhadores atribuírem à instabilidade dos vínculos trabalhistas como um dos fatores que mais repercutiam na saúde mental deles, conforme ilustra a fala de um profissional:

A instabilidade de vínculos é um fantasma constante... isso mexe com a autoestima [...] é uma coisa que magoa. Este é um fantasma constante na vida da gente, é você estar acreditando, gostar tanto e saber que a qualquer momento você não existe mais. (PSICOPEDAGOGA, CAPS 3)

A informalidade e incertezas sobre a situação no trabalho, assim como ausência de benefícios sociais e de proteção da legislação trabalhista são, segundo alguns autores, responsáveis pelo desenvolvimento de ansiedade e depressão nos trabalhadores. (SELIGMANN-SILVA, 1994; LUDEMIR, 2005)

Além das cargas psíquicas decorrentes da insegurança no trabalho, dos vínculos empregatícios instáveis, temporários, ganharam destaque também aquelas relativas ao tipo de trabalho realizado: o contato contínuo com o sofrimento psíquico de outras pessoas. Esse fator foi também mencionado como desencadeador de intenso sofrimento, elevando as exigências emocionais da ocupação.

"A gente lida muito com esse sofrimento do paciente, é um sofrimento que tem continuidade, que acompanha seu dia-a-dia". (PSICÓLOGO, CAPS 4)

O que pra mim é muito complicado, eu acho que é a coisa do desgaste emocional, eu tenho um atendimento que me mobiliza muito às vezes; enfim, porque, eu acho que é isso mesmo, me mobiliza muito. É um pai de um rapaz que era do CAPS ad, que tem um transtorno associado ao uso das drogas, e que bate no pai, O pai é um senhor que não sabe mais o que fazer, e no último atendimento eu disse: eu não sei mais o que fazer para ajudar o senhor! Ele me disse: eu sei, mas eu vim aqui conversar porque eu preciso dividir isso com alguém! É um peso muito grande, eu fico meio emocionada, é um peso. Pra mim é muito pesado, tem dias que chego em casa destruída emocionalmente! [...] de ver a mãe de A., que é uma mulher frágil, né? Cheia de ruguinhas [...]. (TERAPEUTA OCUPACIONAL, CAPS 1)

O convívio com o sofrimento é algo constante no CAPS. O cuidado cotidiano de pessoas portadoras de transtorno mental requer, da equipe de trabalhadores, intenso trabalho de acompanhamento da clientela, 
incluindo aspectos que vão da defesa dos direitos sociais à satisfação de necessidades básicas como a moradia e alimentação. Ou seja, em realidades como a brasileira, onde as desigualdades sociais fazem parte do labutar diário das pessoas, estar exposto diariamente a este sofrimento, às limitações concretas na execução do trabalho, tendo a suposta onipotência do profissional da saúde constantemente posta em cheque por contextos de precariedade em que não é possível resolver os problemas dos pacientes (nem mesmo aqueles cuja solução já é bem conhecida) pode causar sofrimento e frustração. O profissional de saúde, ao conviver com o sofrimento alheio, pode desencadear uma revivência de momentos de sofrimentos pessoais, pois conviver com o sofrimento pode gerar sofrimento. $\mathrm{O}$ trabalhador lida com gente, doente e sofrendo psiquicamente no cotidiano da clínica e, muitas vezes, frente a conflitos intensos dos pacientes e familiares. Desse modo, o temor de ser invadido por ansiedade intensa e incontrolada pode estar presente na própria natureza do trabalho. (PITTA, 2003; LAGO; CODO, 2010)

Outro aspecto que deve ser levado em consideração no trabalho desenvolvido no CAPS refere-se, dentre os ensinamentos sobre a clínica desenvolvida nestes novos dispositivos, ao "modo CAPS de operar o cuidado". Este modo e a noção de "clínica ampliada" ou "clínica da reforma" $i m p l i c a$ íntima relação do serviço, ou seja, do trabalhador com a comunidade e com o sofrimento psíquico apresentado pelo paciente. Essa estreita ligação é compreendida como elemento central na promoção das mudanças e evolução no quadro do paciente, com ênfase na noção de cuidado. (PITTA, 1996; LEAL et al., 2007; BOFF, 2008)

Essa relação de cuidado pode colocar em risco a saúde do trabalhador, no momento em que envolve proximidade (que pode gerar confusão e fusão com o outro), revelando que todos são humanos, podendo padecer dos mesmos males - o profissional de saúde mental se vê compelido a ouvir e suportar um conjunto de angústias, de conflitos, de obstáculos diante de cada ato, de cada pessoa com quem se defronta na prática.

3 Expressão encontrada em texto de Leal e colaboradores (2007) e Delgado (1989). Segundo esses autores, "clinica da reforma" se deve à palavra reforma, referindo-se a uma clinica da Reforma Psiquiátrica brasileira, observam também que a expressão "clinica da reforma" aparece como sinônimo das seguintes expressões: "clinica da atenção psicossocial", "clinica ampliada", "clinica do cotidiano". 


\section{Cargas sociais - exposição à violência}

A partir da reconstrução do processo de trabalho nos CAPS emergiu um novo tipo de exposição ocupacional que foi denominada de "carga social". Estas cargas estavam presentes no ambiente externo de trabalho, quando os trabalhadores dedicavam-se às intervenções fora do local de trabalho, na comunidade: o trabalho de matriciamento, de busca ativa e de visita à residência dos usuários.

As cargas advindas dessa nova exigência do trabalho se caracterizavam pela insegurança com relação à proteção, integridade física e psíquica dos trabalhadores, deflagrada por situações de vulnerabilidade e de violência, às quais estes trabalhadores encontravam-se expostos quando entravam em comunidades lideradas por pessoas envolvidas com o tráfico de drogas ou trabalhavam em unidades situadas em comunidades consideradas perigosas. Esta carga foi insistentemente trazida à discussão, sendo de extrema importância no relato dos trabalhadores, que a apontaram como situação de grande vulnerabilidade social às quais estavam expostos.

As tarefas que mais apresentam riscos são as intervenções externas, porque quando a galera sai pra fazer uma intervenção domiciliar, sai ela e ela munida dela, no nível dela e do colega do lado e do motorista, então a gente não tem nenhum mecanismo de defesa que não seja a gente sair correndo e gritar por socorro. (COORDENADORA, CAPS 1)

Segundo os profissionais, o nível de tensão causado pela insegurança nas imediações do local de trabalho é outro fator muito estressante. Os relatos evidenciaram que muitos profissionais foram ameaçados por moradores de rua que viviam nas imediações das unidades dos CAPS, além de se preocuparem em serem agredidos dentro da unidade:

É essa galera que fica aqui na sinaleira, pedindo dinheiro, que entra aqui e ameaça a gente, e depois a gente vai pegar o ônibus aí na frente onde eles estão. Outro dia uma colega saiu, o rapaz veio aqui ameaçar todo mundo e ela não teve coragem de sair pra trabalhar, ficou esperando o motorista chegar pra ir embora, então isso é estressante, isso é complicado pra qualidade do serviço. Eles, já jogaram "xixi” aqui, porque já tiveram dias em que a gente não tinha segurança e [...] porque a gente já tava tantos dias sem segurança, numa tensão tão grande que ficamos, eu e uma colega, aqui na porta, entrincheiradas pra vigiar, e qualquer pessoa que entrasse a gente gritasse. Já teve a situação de estarmos sem segurança e as meninas estarem aqui na sala e 
entrar uma pessoa que não é do CAPS e se trancar aqui. Então, assim, isso é estressante, não é o usuário, não é o nosso usuário. (TERAPEUTA OCUPACIONAL, CAPS 1)

[...] risco, existe. Aqui a gente já teve problema no momento em que eu fui tentar conter um usuário e eu tava sozinha, eu tava errada porque fui tentar fazer sozinha e me machuquei, ele me machucou, não foi intencionalmente "vou te machucar", mas, e aí? No momento em que eu tentei segurar ele pra que ele não saísse daquele jeito, ele saiu me arrastando e me machucou, mas não foi nada grave, mas é, acontece. (TERAPEUTA OCUPACIONAL, CAPS 1)

A vida do profissional que vive na comunidade onde trabalhava, elevava ainda mais a percepção de risco e de insegurança:

Eu falo enquanto profissional e moradora da região, desta comunidade. Hoje eu me deparo com situações de uso de drogas e questionar com o usuário, lidar com a situação [...] questionar sobre o tráfico e me lembrar que estou na comunidade [...] Hoje em dia eu me questiono: meu filho de três anos estuda aqui próximo ao CAPS, eu deixo ele na escola e venho para o CAPS andando. E aí os usuários podem saber onde moro, onde meu filho estuda e como é isso em outras situações sociais? (ASSISTENTE SOCIAL, CAPS 2)

As questões de violência, portanto, apareceram como uma carga de significativa magnitude entre os trabalhadores e ocorrem de diferentes fontes:

1. Da população excluída socialmente que circula em torno dos locais de trabalho;

2. Dos usuários dos serviços que podem ficar violentos em algumas situações;

3. Das comunidades em que os serviços estão inseridos, muitas vezes dominadas pelo tráfico de drogas.

Esta violência vivenciada pelos trabalhadores dos CAPS, na maioria das vezes ocultada pela falta de sinais e sintomas característicos de uma situação típica de violência, não é reconhecida. Estudos apontam que a exposição prolongada a essas condições pode gerar situações duradouras de perda de iniciativa e de passividade, por vezes, patogênicas e prejudiciais tanto para o trabalhador, quanto para as instituições, sobretudo, quando a eficácia do trabalho requer um engajamento ativo deste. Portanto, quando os trabalhadores de saúde mental, "munidos deles mesmos" (como eles próprios referem) saíam para o trabalho externo, 
conviviam frequentemente com comunidades consideradas de risco, sem contar com os aparatos de proteção necessários. Eles se utilizavam das experiências passadas para constituir maneiras próprias de lidar com a situação e, assim, enfrentar os conflitos cotidianos, ou se sentiam socialmente vulneráveis, o que, por sua vez, desencadeava sofrimento psiquico. (FRANCO, 2004; LANCMAN et al., 2007; DEJOURS, 2009)

\section{Os problemas de saúde}

Uma queixa recorrente foi a de infecção constante por escabiose. Os profissionais relataram que não usavam luvas descartáveis durante os momentos de contato físico com os pacientes e que isto acabava sendo fonte de contínuas infecções e problemas de pele para os trabalhadores. Apontaram ainda que, embora esse fosse um assunto delicado, era uma realidade que a gestão precisava considerar e buscar soluções para equacionar o problema, especialmente porque parecia espelhar um paradigma de que o doente mental não sofre de outras enfermidades clínicas. Apenas considerar que era preconceituoso o uso de luvas para o contato com os pacientes, ou o seu inverso, negar que havia um problema concreto envolvido, eram posicionamentos que negavam a ideia de que o paciente fosse visto em suas várias dimensões (corpo e mente).

Dentre as queixas referentes à própria saúde ganharam destaque os relatos de nervosismo, insônia, sintomas depressivos e hipertensão arterial. Dados da literatura apontam que grande parte das reações adversas à saúde ocorre quando a demanda do trabalho é alta e o grau de controle do trabalhador sobre o trabalho é baixo. (ARAÚJO; CERQUEIRA; ARAÚJO, 2003) Estudos brasileiros com profissionais de saúde mental como os de Nogueira-Martins (2002), De Marco e colaboradores (2008) e de outras categorias profissionais do setor de serviços como Fernandes e colaboradores (2002), Araújo e colaboradores (2003), Reis e colaboradores (2005), Montanhol, Tavares e Oliveira (2006), Tomasi e colaboradores (2008) e Schmidt e colaboradores (2009), encontraram resultados coerentes com essa hipótese de que situações envolvendo elevadas demandas e baixo controle são nocivas à saúde física e mental. 
Outra queixa relevante foram as infecções urinárias, comumente relacionadas às restrições de tempo, de cadência da organização do trabalho (ritmos acelerados) ou de condições inadequadas do ambiente laboral (instalações com precária higienização).

"Eu mesma quando estou aqui trabalhando, não vou ao banheiro, então eu saio daqui meio dia para chegar em outro lugar, apertada". (ENFERMEIRA, CAPS 2)

Foi relatado que as condições higiênicas nos banheiros não eram adequadas, o que fazia com que muitos dos técnicos evitassem o uso dos mesmos ou não bebessem água durante a estadia no serviço.

Os trabalhadores referiram ocorrência de dores de cabeça constantes e as relacionavam com a tensão permanente no serviço. Segundo relatos, nos últimos meses que antecederam a coleta de dados, haviam sido nomeados novos gerentes dos serviços e estes, por sua vez, tinham pouca ou nenhuma experiência em gestão de serviços de saúde mental. Esses novos gestores conduziam o trabalho em moldes verticalizados, marcado por posições autoritárias, nas quais as sugestões dos profissionais não eram aceitas, inibindo, assim, qualquer ação nova do trabalhador, o que gerava tensões relevantes.

Como consequência, observou-se, que em alguns CAPS, houve uma desestruturação das equipes em decorrência das mudanças na forma de conduzir a política de saúde mental, trazendo incoerência e contradições entre os saberes, práticas dos trabalhadores e o modelo de gestão adotado, como se pode observar nas falas dos trabalhadores:

[...] eu tive problemas com a direção porque atendi individualmente um paciente. Eu coloquei isso no relatório e fui chamada pelo gerente que me disse que meu relatório estava errado! Ele disse que em CAPS só podemos fazer atendimento grupal. (ASSISTENTE SOCIAL, CAPS 2)

[...] acontece que os chefes não têm visão e ficam querendo cobrar apenas o horário. (FISIOTERAPEUTA, CAPS 2)

A gestão do trabalho aparece como um elemento ordenador do fazer em saúde mental, ficando evidente o grau de dependência da aderência ou não do gestor às práticas inovadoras defendidas pelo novo modelo. Portanto, uma nova fragilidade se revelou na cena do trabalho: o modelo avançará mais ou menos a depender da correlação de forças que estava estabelecida em cada local de trabalho. Nesse ponto, a ca- 
pacidade de cooperação e de coesão das equipes de trabalho exerce papel central. Quanto mais integrada for a equipe, menos vulnerável será o processo de implantação do novo modelo. No entanto, a existência de vínculos laborais frágeis, temporários, despontou como obstáculo maior nas possibilidades de coesão das equipes. Assim, este dilema aparece como um desafio marcante a ser enfrentado.

As informações obtidas a respeito da percepção dos trabalhadores com referência a relação entre saúde e trabalho nas unidades, permitiram identificar que esta era percebida como precária, e até mesmo de vulnerabilidade. Segundo estes trabalhadores, havia falta de interesse dos gestores em tomar conhecimento sobre suas reais condições de trabalho.

[...] na verdade, esta administração nunca veio aqui pra procurar ver a situação do CAPS, do atendimento, das nossas necessidades, como a gente está se sentindo nesse lugar que a gente foi colocado". (ASSISTENTE SOCIAL, CAPS 4)

No discurso dos trabalhadores emergiu a queixa sobre a invisibilidade do profissional/técnico. Observou-se, contudo, que não era propriamente o técnico de saúde mental que era invisível, mas sim o seu trabalho, que se tornava invisível para os gestores, na medida em que não era materializado em produtos concretos, palpáveis. Ou seja, boa parte do trabalho realizado não era passível de ser mensurado em procedimentos; portanto, não era contabilizada nas planilhas de serviços executados - conforme exigência dos órgãos competentes. Essa porção imaterial do trabalho, embora essencial para a atenção em saúde mental, mantinha-se invisível, não contabilizada. (LANCMAN, 2008) Assim, o trabalho real, executado cotidianamente, era invisível aos gestores, porque não resultava em indicadores de produtividade ou de qualidade compatíveis com o processo de produção, nem com o valor do serviço realizado. Essa lógica de avaliação do trabalho conformava situações de sofrimento e inadequação nos trabalhadores: o necessário para o bom desempenho no trabalho chocava-se com os indicadores de valorização adotados pela gestão, colocando em risco o reconhecimento das etapas e dos recursos necessários à operacionalização do trabalho em saúde mental.

A dinâmica do reconhecimento pode acontecer de duas maneiras: a primeira é denominada de reconhecimento de utilidade, sendo realizada 
pelos níveis hierárquicos superiores e pelo usuário do serviço ofertado; a segunda é denominada de julgamento estético, realizada pelos colegas de trabalho, por aqueles que conhecem a especificidade do trabalho e podem avaliar o esforço despendido pelo trabalhador em realizá-lo. A ausência ou dificuldades desses processos de reconhecimento podem acarretar falhas no desenvolvimento da identidade do indivíduo e nas possibilidades de transformação do sofrimento gerado pelo trabalho em prazer. (FRANCO, 2004; LANCMAN, 2008; DEJOURS et al., 2009)

A falta de suporte psicológico estabeleceu-se como fator capaz de desagregar a saúde mental dos trabalhadores:

"Nós precisamos de suporte. Eu tenho meu suporte psicanalítico, que eu acho que se não fosse isso, eu não ia conseguir". (TERAPEUTA OCUPACIONAL, CAPS 2)

Nós já tivemos supervisão clínico-institucional, foi um período que ajudou bastante o grupo. Na época, trazíamos as angústias do cotidiano e aí de alguma forma a supervisão nos dava um suporte! A supervisão é o instrumento! (PSICÓLOGA, CAPS 2)

Diante dos discursos dos trabalhadores pode-se concluir que o momento é de muita dificuldade institucional, aparentemente resultado da ausência de medidas de apoio para as equipes de trabalhadores. Desde 2004, em São Paulo, no I Congresso Brasileiro de CAPS, já havia incentivos para projetos de Supervisão Clínico-Institucional de CAPS. No entanto, como mostram nossos dados, as situações em que se contava com esse apoio ainda era exceção.

\section{Potencialidade e limites dos processos de trabalho em saúde mental}

$\mathrm{Na}$ avaliação sobre as potencialidades e os limites do trabalho nos CAPS, os profissionais relataram que a reconstrução psíquica dos pacientes e o reconhecimento recebido da família e do usuário constituíam as maiores fontes de prazer na realização do trabalho. No discurso dos trabalhadores, o fato de poder oferecer bom atendimento e de poder ajudar o paciente ou a sua família a melhorar suas condições de saúde e de vida eram fatores que proporcionavam muito prazer no trabalho. 
Teve ocasião em que eu chorei mesmo! Porque a gente está fragilizada e às vezes embola tudo, não é que você vai se envolver com as questões do paciente, mas você sai mexida mesmo e não consegue manter a neutralidade o tempo todo! (PSICÓLOGO, CAPS 4)

A necessidade de formação e qualificação dos trabalhadores foi pautada em todas as entrevistas. Os trabalhadores fizeram referência à necessidade de capacitação de recursos humanos, como uma forma de se adequarem para o enfrentamento das novas estratégias em saúde mental.

“[...] assim, aprendi que somos técnicos em saúde mental, aí temos um nome, que bom! Senão seria uma coisa assim, todo mundo faz tudo. (ENFERMEIRA, CAPS 3)

A princípio, para quem nunca trabalhou neste sistema, é meio que desorganizador, porque a gente fica meio perdida, meio confusa. Mesmo porque não há uma preparação anterior. Não tem capacitação. A gente vai se capacitando e contando com a boa vontade de quem já está ali, né? Eu acho que é um perigo e ao mesmo tempo exige destes profissionais um dinamismo, um interesse, é uma faca de dois gumes [...] eu acho que, quem trabalha em CAPS está preparado para trabalhar em qualquer lugar. (ENFERMEIRA CAPS 3)

Estes resultados estão em concordância com estudos realizados no Brasil sobre a formação específica de trabalhadores em saúde mental. Segundo as pesquisas, a ausência ou insuficiência na formação para a atuação em saúde mental, sobre novo paradigma, tem sido destacada como obstáculo às mudanças preconizadas. (OLIVEIRA et al., 2003; BISCHAF, 2006)

Uma estratégia encontrada para o enfrentamento da falta de formação e capacitação continuada foi, segundo os trabalhadores, a troca de informações e textos.

"Eu acho que tem um longo caminho ainda. Falta muita coisa a nível de rede, a nível de informação, entendeu? A própria capacitação dos profissionais que trabalham, pois capacitados eles levam junto o CAPS". (ASSISTENTE SOCIAL, CAPS 6)

"[...]nós procuramos nos especializar, ler e nos informar". (EDUCADOR FÍSICO, CAPS 4)

Os trabalhadores se organizavam para que, nas reuniões de equipe, algum tempo pudesse ser disponibilizado para a discussão de textos técnicos. Deve-se pontuar que desde a II Conferência Nacional de 
Saúde Mental, realizada em dezembro de 1992, se enfatiza a necessidade de garantir práticas de ensino, pesquisa e extensão que poderiam favorecer "novas atitudes dos futuros profissionais em relação à doença mental e que estimulem o desenvolvimento do potencial dos indivíduos com sofrimento psíquico"; No entanto, em Salvador, as capacitações foram feitas de forma pontual e não atingiram a todos os trabalhadores dos CAPS, como mencionado pelos trabalhadores.

\section{Considerações finais}

A descrição dos processos de trabalho de um setor laborativo ou a avaliação do trabalho de uma categoria profissional implica sempre no temor de não conseguir englobar os aspectos envolvidos no trabalho em sua totalidade.

A análise das cargas de trabalho evidenciou que os fatores mais relevantes para o desgaste dos trabalhadores estavam relacionados à inadequação dos espaços utilizados, especialmente a infraestrutura física dos locais de trabalho, às cargas psíquicas, entre essas a insegurança no trabalho. Este último elemento incluiu dois tipos de insegurança: um relacionado ao tipo de vínculo empregatício, ocasionada por contratos de trabalho temporários; e a insegurança com relação à proteção e integridade física e psíquica dos trabalhadores, deflagrada por situações de vulnerabilidade e de violência.

Nesta investigação, partiu-se do pressuposto de que, mesmo com quase uma década de discussão e trabalho, os desafios continuam sendo muitos, envolvendo diferentes dimensões.

Segundo Dejours e colaboradores (2009), o trabalho deve ser entendido como um continuum que se estende para além de seu espaço restrito e influencia outras esferas da vida. As relações que ocorrem no trabalho constituem uma grande fonte de desenvolvimento da identidade do indivíduo e da transformação do sofrimento em prazer, por meio dos vários processos de reconhecimento. Quando o reconhecimento do seu fazer não ocorre, a desvalorização pode atingir outros espaços da vida cotidiana, portanto, o compromisso com os trabalhadores é fundamental para a manutenção desses serviços e, por conseguinte, é necessário por parte dos gestores, manter a motivação desses, 
reconhecendo-os como os principais agentes das práticas e políticas de saúde mental.

Observou-se que, como o trabalho em saúde mental pode ser desestabilizador, é necessário que se criem espaços de trocas, que funcionem como ponto de apoio para as equipes e que fortaleçam as estratégias de cooperação; sendo neste caso a supervisão de equipes de suma importância para a saúde mental dos trabalhadores.

Não obstante, devem ser mencionadas as dificuldades administrativas e financeiras para a operacionalização destas modificações, considerando o atual cenário político nacional, onde se preconiza atualmente o corte de verbas para a saúde mental, pressionando estados e municípios a trabalharem com verbas mínimas neste setor. (BICHAFF, 2006)

Finalmente, destacou-se que se faz necessário, assim como preconiza a política de saúde mental, que os trabalhadores possam contar com uma política de recursos humanos e gestão do trabalho que contemple a democratização das relações de trabalho e das discussões em todos os níveis de gestão, que haja condições de melhoria dos processos de trabalho, que se incorpore a questão da segurança do trabalhador, a saúde e saúde mental, que seja institucionalizada a supervisão clínica e institucional, que a jornada de trabalho seja adequada para todos os profissionais, assim como a isonomia salarial entre eles, e que, desta forma, se combata a precarização das relações de trabalho existentes atualmente.

\section{Referências}

ARAÚJO, T. M. CERQUEIRA, C. G.; ARAÚJO, E. M. Estresse ocupacional e saúde: contribuições do modelo demanda-controle. Ciências e Saúde Coletiva, v. 8, n. 4, p. 991-1003, 2003.

ARAÚJO, T. M. O olhar do sujeito sobre o trabalho que executa: sua percepção sobre os riscos e as tarefas. In: SAMPAIO, J. R. (Org.). Qualidade de vida, saúde mental e psicologia social - Estudos Contemporâneos II. São Paulo: CASA DO PSICÓLOGO, 2004.

BARDIN, L. Análise de conteúdo. Lisboa: Edições 70, LDA, 2009.

BICHAFF, R. O trabalho nos centros de atenção psicossocial: uma reflexão crítica das práticas e suas contribuições para a consolidação da reforma psiquiátrica. 2006, 217f. Dissertação 
(Mestrado em Enfermagem Psiquiátrica). Escola de Enfermagem, Universidade de São Paulo, São Paulo, 2006.

BRASIL. MINISTÉRIO DA SAÚDE. Secretaria de Atenção à Saúde. Departamento de Ações Programáticas. Saúde Mental no SUS:

Os Centros de Atenção Psicossocial. Brasília: Ministério da Saúde, 2004.

BOFF, L. Saber cuidar - ética do humano - compaixão

pela terra. 15. ed. Rio de Janeiro: Vozes, 2008.

COUTINHO NETO, O. B. Estudo sobre cargas de trabalho e processo de desgaste das auxiliares de enfermagem em um hospital universitário de Pernambuco. 1998. 60f. Dissertação (Mestrado em Saúde Coletiva). CPQAM, FIOCRUZ - Departamento de Saúde Coletiva/NESC, Recife, 1998.

DE MARCO, P. F. et al. O impacto do trabalho em saúde mental: transtornos psiquiátricos menores, qualidade de vida e satisfação profissional. Jornal Brasileiro de Psiquiatria, São Paulo, v. 57, n. 3, p. 178-183, 2008.

DEJOURS, C. et al. Psicodinâmica do trabalho. São Paulo: Atlas, 2009.

DELGADO, P. Projeto de Lei nº 367/89. Brasília, 1989.

FACCHINI, L. A. et al. Modelo operário e percepção de riscos ocupacionais e ambientais: o uso exemplar de estudo descritivo. Revista de Saúde Pública, v. 25, n. 5, p. 394-400, 1991. . Uma contribuição da Epidemiologia: o modelo da determinação social aplicado à saúde do trabalhador. In: ROCHA, Lys Esther et al. (org. ) Isto é trabalho de gente? Vida, Doença e Trabalho no Brasil. São Paulo: Vozes, 1993.

FERNANDES, R. C. P. et al. Trabalho e cárcere: um estudo com agentes penitenciários da Região Metropolitana de Salvador, Brasil. Caderno de Saúde Pública, v. 18, n. 3, p. 807-816, 2002.

FRANCO, T. A centralidade do trabalho na visão da psicodinâmica de Dejours. Caderno CRH, v. 17, n. 41, p. 309-321, 2004.

LAGO, K.; CODO, W. Fadiga por compaixão: o sofrimento dos profissionais de saúde. Petrópolis-RJ. : Vozes, 2010.

LANCMAN, S. et al. O trabalho na rua e a exposição à violência no trabalho: um estudo com agentes de trânsito. Interface Comunicação, Saude, Educação, v. 11, n. 21, p. 79-92, 2007. . (Org. ). Políticas públicas e processos de trabalho em saúde mental. Brasília: Paralelo 15, 2008. 
LAURELL, A. C.; NORIEGA, M. Para o estudo da saúde na sua relação com o processo de trabalho. In: Processo de produção e saúde. Trabalho e desgaste operário. São Paulo: Hucitec, 1989.

LEAL, E. M. et al. Clínica e cotidiano: o CAPS como dispositivo de desinstitucionalização. In: PINHEIRO, R. et al. Desinstitucionalização da saúde mental: contribuições para estudos avaliativos. CEPESCIMS/UERJ-ABRASCO. Rio de Janeiro, p. 137-158, 284, 2007.

LUDEMIR, A. B. Associação dos TMC com a informalidade das relações de trabalho. Jornal Brasileiro de Psiquiatria, v. 54, n. 3, p. 198-204, 2005.

MILHOMEN, M. A. G. C. et al. , O trabalho em equipe nos Centros de Atenção Psicossocial - CAPS. Cogitare Enfermagem, v. 12, n. 1, p. 101-108, 2007.

MINAYO, M. C. O desafio do conhecimento: pesquisa qualitativa em saúde. São Paulo: Hucitec, 2008.

MONTANHOLI, L. L.; TAVARES, D. M. S.; OLIVEIRA, G. R. Estresse: fatores de risco no trabalho do enfermeiro hospitalar. Revista Brasileira de Enfermagem, v. 59, n. 5, p. 661-665, 2006.

MONTEIRO, D. A. A função dos ambulatórios de psiquiatria no processo de construção da reforma psiquiátrica, nos SUS, em Salvador. Projeto de qualificação. Instituto de Saúde Coletiva, Universidade Federal da Bahia, 2007.

NOGUEIRA-MARTINS, M. C. F. A experiência de supervisão de hospitais em um Programa de Humanização. In: CONGRESSO Brasileiro de Psicologia Ciência e profissão, I. Anais... São Paulo, 2002.

OLIVEIRA, A. G. B. et al. A reforma psiquiátrica e o processo de trabalho das equipes de saúde mental. Revista Paulista de Enfermagem, v. 22, p. 31-42, 2003.

PEDUZZI, M. Trabalho em equipe de saúde da perspectiva de gerentes de serviços de saúde: possibilidades da prática comunicativa orientada pelas necessidades de saúde dos usuários e da população. 2007, 247f. Tese (Doutorado em enfermagem) Escola de Enfermagem, Universidade de São Paulo, USP, 2007.

PITTA, A. M. F. Reabilitação psicossocial no

Brasil. São Paulo: Hucitec, 1996. . Hospital: dor e morte como ofício. 5. ed. São Paulo: Hucitec, 2003. RABELO, A; COUTINHO, D. M. Análise da Saúde Mental no Estado da Bahia. Gazeta Médica da Bahia, v. 78, n. 2, p. 104-119, 2009. 
RAMMINGER, T. Trabalhadores de saúde mental: reforma psiquiátrica, saúde do trabalhador e modos de subjetivação nos serviços de saúde mental, 2005. 118f. Dissertação (Mestrado em psicologia) Instituto de Psicologia, Universidade Federal do Rio Grande do Sul, Porto Alegre, 2005.

REIS, E. J. F. B. et al. Trabalho e distúrbios psíquicos em professores da rede municipal de Vitória da Conquista, Bahia, Brasil. Cadernos de Saúde Pública, v. 21, n. 5, p. 1480-1490, 2005.

SELIGMANN-SILVA, E. Desgaste Mental do

Trabalho. São Paulo: Cortez Editora. 1994.

SCHMIDT, D. R. C. et al. Estresse ocupacional entre profissionais de enfermagem do bloco cirúrgico. Texto \& Contexto Enfermagem, Florianópolis, v. 18, n. 2, p. 330-337, jun. 2009.

TOMASI, E. et al. Perfil sociodemográfico e epidemiológico dos trabalhadores da atenção básica à saúde nas regiões Sul e Nordeste do Brasil. Caderno de Saúde Pública, v. 24, p. 193-201, 2008.

YASUI, S. CAPS: estratégia de produção de cuidado e de bons encontros. In: PINHEIRO, R. et al. Desinstitucionalização da saúde mental: contribuições para estudos avaliativos. 1 ed., CEPESC-IMS/UERJ-ABRASCO. Rio de Janeiro, 2007. 